07

\title{
Высокоэффективные AIGaAs/GaAs фотоэлектрические преобразователи с торцевым вводом лазерного излучения
}

\author{
(C) В.П. Хвостиков, П.В. Покровский, О.А. Хвостикова, \\ А.Н. Паньчак, В.М. Андреев
}

Физико-технический институт им. А.Ф. Иофре РАН, Санкт-Петербург, Россия

E-mail: vlkhv@scell.ioffe.ru

Поступило в Редакцию 23 мая 2018 г.

Разработаны и созданы методом жидкофазной эпитаксии высокоэффективные фотоэлектрические преобразователи (ФЭП) в системе $\mathrm{AlGaAs}-\mathrm{GaAs}$ с вводом лазерного излучения $(\lambda=850 \mathrm{~nm})$ с торцевой поверхности параллельно плоскости $p-n$-перехода приборной структуры. Для увеличения эффективности „захвата“ света $p-n$-переходом сформирован волноводный слой $\mathrm{Al}_{x} \mathrm{Ga}_{1-x} \mathrm{As} \mathrm{c}$ плавным изменением содержания алюминия от $x=0.55$ до 0.15 , обеспечивающий создание градиента показателя преломления в этом слое и отклонение лучей света к $p-n$-переходу. При засветке ФЭП (без антиотражающего покрытия) лазерным излучением мощностью $0.1-0.2 \mathrm{~W}$ получен КПД 41.5\%. Просветление торцевой поверхности ФЭП обеспечивает повышение КПД разработанного ФЭП до 55\%.

DOI: 10.21883/PJTF.2018.17.46569.17400

Мощные фотоэлектрические преобразователи (ФЭП) концентрированного солнечного излучения [1] и мощного лазерного излучения [2] все больше применяются в солнечной энергетике и системах беспроводной передачи энергии по лазерному лучу. В последние годы ведутся активные разработки высокоэффективных ФЭП мощного лазерного излучения [3-6], работающих в фотовольтаическом режиме без приложения внешнего смещения.

На рис. 1 показаны ФЭП двух конструкций: с традиционным вводом излучения перпендикулярно плоскости $p-n$-перехода $(a)$ и с торцевым вводом излучения параллельно плоскости $p-n$-перехода $(b)$. В первом случае на фронтальной поверхности мощных фотопреобразователей 
$a$

$b$
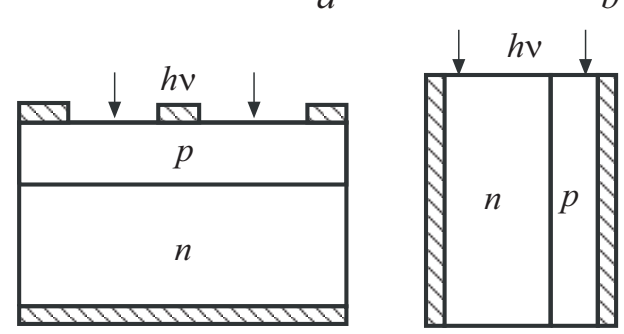

$c$

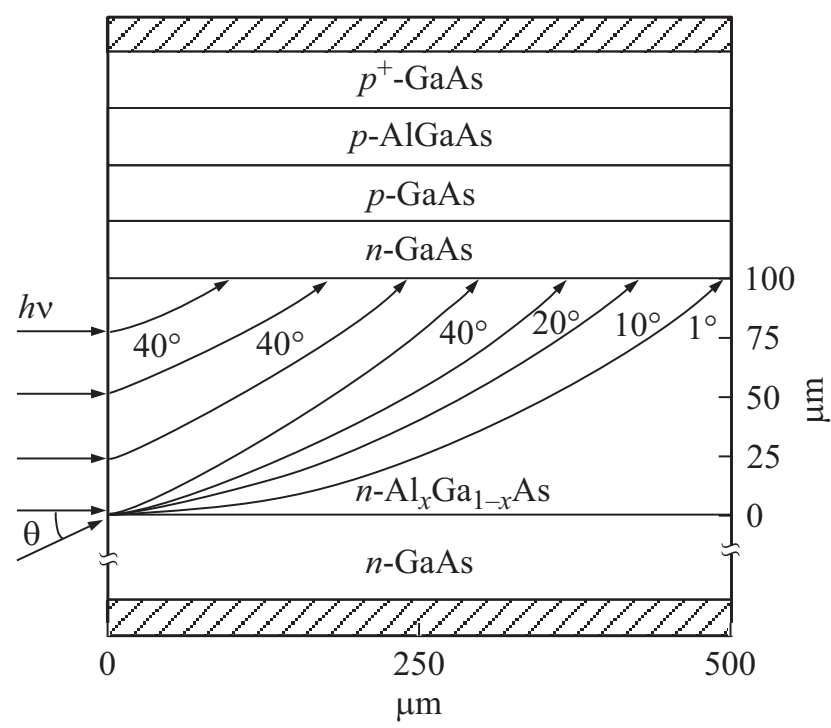

Рис. 1. Схематическое изображение различных конструкций фотопреобразователей: $a-\mathrm{c}$ традиционным вводом излучения, $b-\mathrm{c}$ торцевым вводом излучения, $c$ - конструкция разработанного фотопреобразователя с расчетными траекториями лучей света в волноводном слое $n$-AlGaAs толщиной $100 \mu \mathrm{m}$ при различных углах $\theta$ ввода лазерного излучения.

необходимо создание системы полосковых омических контактов, что неизбежно приводит к дополнительным оптическим потерям вследствие затенения фотоактивной поверхности контактной сеткой. Во втором

Письма в ЖТФ, 2018, том 44, вып. 17 
варианте излучение вводится в фотопреобразователь с торца через поверхность, полученную скалыванием (аналогично созданию плоскопараллельных торцов полупроводникового лазера), либо через вытравленную с помощью фотолитографии боковую поверхность чипа ФЭП. Ввод излучения параллельно плоскости $p-n$-перехода позволяет уменьшить на 5-10\% оптические потери на затенение полосковыми контактами, a также снизить приблизительно на порядок омические контактные потери за счет формирования сплошных металлических контактов на фронтальной и тыльной поверхностях фотоэлемента. Конструкция ФЭП с торцевым вводом излучения, т.е. с вертикальным $p$ - $n$-переходом (рис. $1, b)$, широко используется при изготовлении кремниевых фотопреобразователей [7]. Для ФЭП на основе материалов группы $\mathrm{A}^{\mathrm{III}} \mathrm{B}^{\mathrm{V}}$ сделана теоретическая оценка таких фотопреобразователей для случая гетероструктуры $\mathrm{AlGaAs} / \mathrm{GaAs}$ на подложке $p$-типа проводимости [8].

Задачей настоящей работы является разработка и создание методом жидкофазной эпитаксии высокоэффективных фотоэлектрических преобразователей в системе $\mathrm{AlGaAs}-\mathrm{GaAs}$ с вертикальным $p-n$-переходом, т. е. с вводом лазерного излучения $(\lambda=850 \mathrm{~nm})$ с торцевой поверхности приборной структуры ФЭП, выращенной на подложке $n$-типа проводимости.

На рис. 1, с представлена структура разработанного нами ФЭП. Важной особенностью структуры является создание широкозонного волноводного слоя с плавным изменением коэффициента преломления твердого раствора $n-\mathrm{Al}_{x} \mathrm{Ga}_{1-x} \mathrm{As}$ за счет плавного изменения содержания $\mathrm{Al}$ в слое $n-\mathrm{Al}_{x} \mathrm{Ga}_{1-x} \mathrm{As}$, что приводит к отклонению лучей света, введенных в этот слой, к $p$-n-переходу. На рис. 1, $c$ приведены рассчитанные траектории лазерных лучей в волноводном слое $\mathrm{Al}_{x} \mathrm{Ga}_{1-x} \mathrm{As}$ толщиной $100 \mu \mathrm{m}$, в котором показатель преломления изменяется от $n=3.2$ в слое со значением $x=0.55$ на границе с подложкой до $n=3.5$ в слое с $x=0.15$ на границе со слоем $n$-GaAs. Градиент концентрации AlAs в таком слое составляет величину $0.4 \mathrm{~mol} \%$ на $1 \mu \mathrm{m}$. Все лучи, вошедшие в волноводную область, отклоняются в область $p-n$-перехода прежде, чем они достигнут противоположного торца структуры при длине структуры не менее $500 \mu \mathrm{m}$. При толщине волноводного слоя $50 \mu \mathrm{m}$ и значении градиента концентрации AlAs, равном $0.4 \mathrm{~mol} \%$, длина ФЭП, на которой происходит полное отклонение лучей к $p-n$ переходу, составляет $360 \mu \mathrm{m}$.

Письма в ЖТФ, 2018, том 44, вып. 17 
Кроме свойств волноводного слоя на траекторию лучей оказывает также влияние угол $\theta$ их ввода в волноводный слой. Увеличение угла $\theta$ от 1 до $40^{\circ}$ приводит к снижению максимального значения горизонтальной составляющей хода лучей в волноводе от 500 до $300 \mu \mathrm{m}$ при толщине слоя $\mathrm{Al}_{x} \mathrm{Ga}_{1-x} \mathrm{As}$, равной $100 \mu \mathrm{m}$, и от 360 до $190 \mu \mathrm{m}$ при толщине слоя $\mathrm{Al}_{x} \mathrm{Ga}_{1-x} \mathrm{As}$, равной $50 \mu \mathrm{m}$ (рис. $1, c$ ).

Возможность создания сплошных омических контактов к верхней и нижней поверхностям структуры разработанных ФЭП позволяет исключить ряд дополнительных технологических операций, свести к минимуму постростовую обработку структуры для получения ФЭП и улучшить теплоотвод мощных ФЭП. Наряду с этим приблизительно на порядок снижаются омические контактные потери в фотопреобразователе, так как в случае сплошных контактов на порядок увеличивается площадь токосъема по сравнению с площадью токосъемной сетки в ФЭП с традиционным вводом излучения перпендикулярно плоскости $p$-n-перехода.

Для уменьшения оптических потерь на поверхность освещаемого торца ФЭП наносится антиотражающее покрытие $\mathrm{Ta}_{2} \mathrm{O}_{5}$ с минимумом отражения (менее $1 \%$ ) в спектральном интервале $800-870 \mathrm{~nm}$.

Для создания конструкции фотопреобразователя, показанной на рис. $1, c$, на подложке $n$-GaAs последовательно выращивались слои: первый слой с градиентом состава $n-\mathrm{Al}_{x} \mathrm{Ga}_{1-x} \mathrm{As}(x=0.55-0.15)$, затем слой $n$-GaAs, слой $p$-GaAs, слой $p-\mathrm{Al}_{x} \mathrm{Ga}_{1-x} \mathrm{As}(x=0.2-0.1)$ и контактный слой $p^{+}$-GaAs. Использованный метод жидкофазной эпитаксии позволяет выращивать совершенные эпитаксиальные слои толщиной от нескольких нанометров до сотен микрометров в одном технологическом процессе за относительно короткое время кристаллизации (от секунд до нескольких часов). Слои характеризуются высоким качеством за счет того, что рост происходит в условиях термодинамического равновесия. Кристаллизация градиентного слоя $n-\mathrm{Al}_{x} \mathrm{Ga}_{1-x} \mathrm{As}$ толщиной $50 \mu \mathrm{m}$ (с изменением содержания алюминия в волноводном слое от $x=0.55$ на границе с подложкой до $x=0.15$ на гетерогранице со слоем $n$-GaAs) осуществлялась при охлаждении в диапазоне температур от 850 до $600^{\circ} \mathrm{C}$.

В качестве донорной легирующей примеси выбор был остановлен на олове, имеющем меньшее значение парциального давления пара по сравнению с теллуром.

Письма в ЖТФ, 2018, том 44, вып. 17 


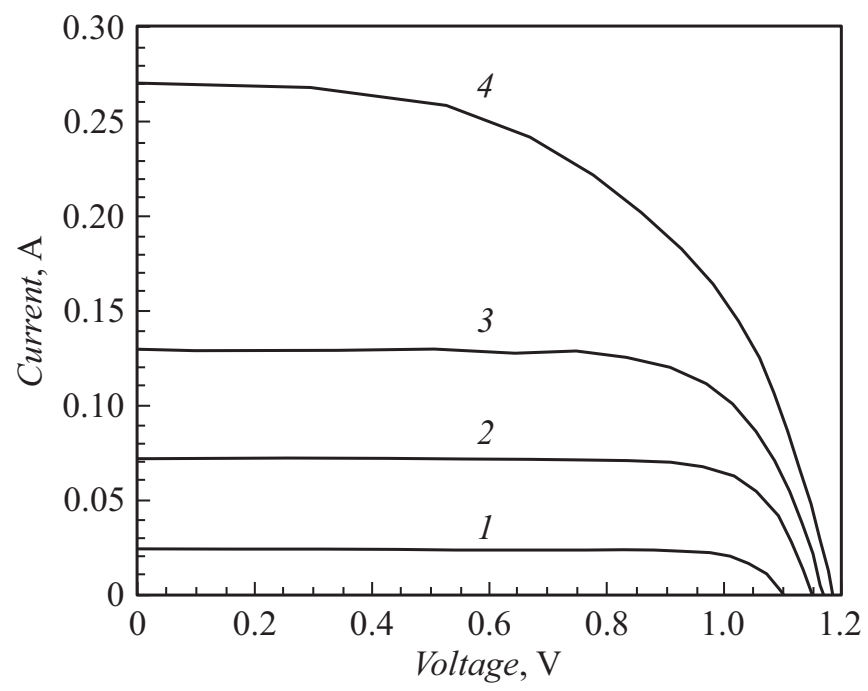

Рис. 2. Семейство световых вольт-амперных характеристик фотоэлектрического преобразователя (без просветляющего покрытия) при засветке лазерным излучением с торцевой поверхности с длиной волны $850 \mathrm{~nm}$ и мощностью 0.05 (1), $0.15(2), 0.28(3), 0.6 \mathrm{~W}(4)$.

В качестве акцепторной примеси был выбран германий, поскольку он в отличие от магния и цинка характеризуется меньшим значением парциального давления пара при температурах проведения эпитаксии. С целью снижения контактного сопротивления ФЭП в конце эпитаксии выращивался контактный слой $p^{+}$-GaAs при температурах роста $600-520^{\circ} \mathrm{C}$. При содержании германия в расплаве галлия 5 at.\% уровень легирования контактного слоя GaAs составил $1 \cdot 10^{19} \mathrm{~cm}^{-3}$, что обеспечило формирование низкоомного контакта.

На рис. 2 представлены световые вольт-амперные характеристики созданного фотоэлектрического преобразователя с торцевым вводом излучения, в котором толщина волноводного эпитаксиального слоя составила $50 \mu \mathrm{m}$. Ввод импульсного лазерного излучения с длиной волны $850 \mathrm{~nm}$ различной мощности от 0.05 до $0.6 \mathrm{~W}$ осуществлялся из оптического волокна диаметром $50 \mu \mathrm{m}$.

Письма в ЖТФ, 2018, том 44, вып. 17 


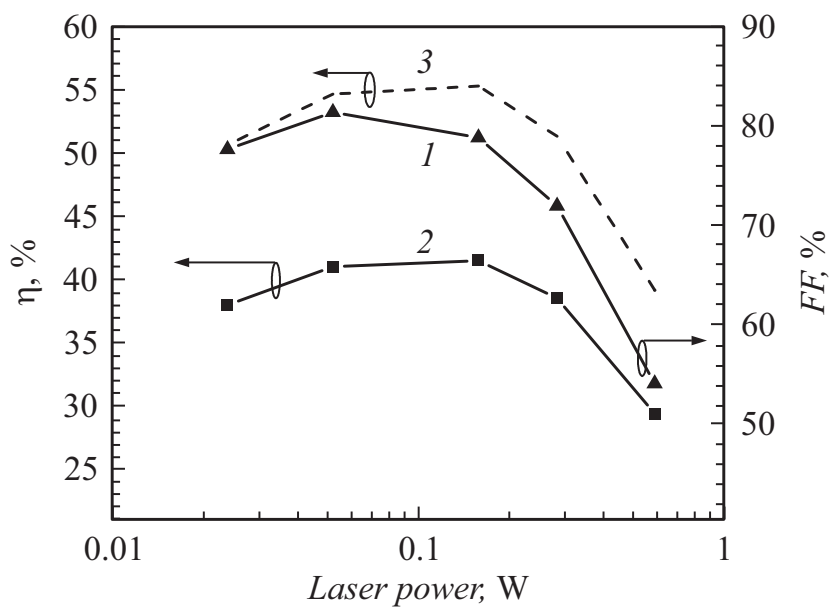

Рис. 3. Зависимость фактора заполнения $(F F)$ вольт-амперных характеристик фотоэлектрического преобразователя $(1)$ и КПД $(\eta)$ без антиотражающего покрытия (2) и с антиотражающим покрытием (3) от мощности излучения при торцевом вводе лазерного излучения $(\lambda=850 \mathrm{~nm})$.

Зависимости эффективности ФЭП и фактора заполнения нагрузочных характеристик от мощности лазерного излучения представлены на рис. 3. Максимальное значение КПД фотоэлектрического преобразования лазерного излучения составило $41.5 \%$ в ФЭП без просветляющего покрытия и $55 \%$ в ФЭП с просветляющим покрытием на торцевой поверхности.

Таким образом, в работе проведено моделирование хода лучей в структуре с торцевым вводом лазерного излучения при линейном изменении содержания алюминия в волноводном слое. Определено, что при вводе излучения под углом $1^{\circ}$ к плоскости роста структуры с толщиной волноводного слоя, равной $100 \mu \mathrm{m}$, минимальная длина ФЭП должна составлять не менее $500 \mu \mathrm{m}$. Увеличение угла ввода излучения до $40^{\circ}$ приводит к уменьшению „эффективной“ длины ФЭП до $300 \mu \mathrm{m}$ и увеличению плотности мощности облучения на $p-n$-переходе. Методом жидкофазной эпитаксии выращены приборные гетероструктуры $\mathrm{AlGaAs} / \mathrm{GaAs}$, на основе которых изготовлены фотоэлектрические преобразователи со сплошным тыльным и фронталь-

Письма в ЖТФ, 2018, том 44, вып. 17 
ным контактами с торцевым вводом лазерного излучения. В ФЭП с толщиной градиентного волноводного слоя, равной $50 \mu \mathrm{m}$, с просветленной торцевой поверхностью при засветке лазерным излучением $(\lambda=850 \mathrm{~nm})$ мощностью $0.1-0.2 \mathrm{~W}$ обеспечено достижение КПД 55\%, что сравнимо с максимальными значениями КПД, полученными в ФЭП с традиционным вводом излучения перпендикулярно плоскости $p-n$-перехода.

Один из путей дальнейшего повышения КПД разработанных $\mathrm{AlGaAs-фотопреобразователей} \mathrm{состоит} \mathrm{в} \mathrm{возможности} \mathrm{согласования}$ ширины запрещенной зоны ФЭП с длиной волны падающего лазерного излучения путем изменения содержания алюминия в фотоактивных слоях в области $p-n$-перехода.

\section{Список литературы}

[1] Andreev V.M., Grilikhes V.A., Rumyantsev V.D. // Photovoltaic conversion of concentrated sunlight. John Wiley \& Sons, 1997. 308 p.

[2] Andreev V., Khvostikov V., Kalinovsky V., Lantratov V., Grilikhes V., Rumyantsev V., Shvarts M., Fokanov V., Pavlov A. // Proc. of WCPEC-3. Osaka, 2003. V. 1. P. 3P-B5-33.

[3] Zhao Y., Sun Y., He Y., Yu S., Dong J. // Sci. Rep. 2016. V. 6. P. 38044.

[4] Андреев В.М. // Современная электроника. 2014. № 6. С. 20-25.

[5] Хвостиков В.П., Сорокина С.В., Потапович Н.С., Хвостикова О.А., Тимошина Н.X. // ФТП. 2017. Т. 51. В. 5. С. 676-679.

[6] Oliva E., Dimroth F., Bett A.W. // Prog. Photovoltaics: Res. Appl. 2008. V. 16. N 4. P. 289-292.

[7] Pozner R., Segev G., Sarfaty R., Kribus A., Rosenwaks Y. // Prog. Photovoltaics: Res. Appl. 2012. V. 20. N 2. P. 197-208.

[8] Kashyap B., Datta A. // IEEE Trans. Electron Dev. 2017. V. 64. N 6. P. 2564 2571. 